\title{
COVID-19: A Review on Recent Pandemic
}

\author{
Jyoti Zingade ${ }^{1}$, Swapna Avula ${ }^{2}$, Pavan K Gujjar ${ }^{3}$, Saroj Thakur ${ }^{4}$
}

\begin{abstract}
The recent outburst of new pandemic disease coronavirus disease 2019 (COVID-19) from Wuhan City, China mainland, suddenly rose between November and December 2019. It has currently become a public health emergency globally as stated by the World Health Organization (WHO) on 11 March 2020. Coronaviruses (CoVs) have been described for more than 50 years ago. CoVs infect many species of animals, including humans. Human CoVs caused only the common cold. However, in the spring of 2003, it became clear that a new human CoV was responsible for the severe acute respiratory syndrome (SARS). The origin of the SARS-CoV poses interesting questions about CoV evolution and species specificity. With the occurrence of the SARS epidemic, CoV may now be considered "emerging pathogens."The main objective of this paper is to review and to enlighten the COVID-19 virus and its pathogenesis. Thus, the present review shows a brief and the basic information about the COVID-19.

Keywords: Coronavirus COVID-19, Middle East respiratory syndrome, SARS-CoV-2.

Journal of Health Sciences \& Research (2021): 10.5005/jp-journals-10042-1102
\end{abstract}

\section{INTRODUCTION}

The name "coronavirus" was termed in 1968, which is derived from the "crown-like" morphology observed for these viruses in the electron microscope. The Coronaviridae family was established in the year 1975 by the International Committee on the Taxonomy of Viruses (ICTV). ${ }^{2}$ Severe acute respiratory syndrome coronavirus 2 (SARS-CoV-2) was the name of the new virus given by the ICTV on February 11,2020 , as it was genetically related but different from the coronavirus (CoV) responsible for the SARS outbreak of 2003. Moreover, the World Health Organization (WHO) named the disease caused by this virus as "COVID-19". ${ }^{3}$

COVID-19 created a public health problem affecting not only China but the whole world. On January 31, 2020, the WHO declared COVID-19 as an international emergency that threatened public health. Later, the infection became much more widespread, so WHO updated the situation, declaring COVID-19 as a pandemic on March $12,2020 .{ }^{4}$ It is a zoonotic disease, which constitutes a large group of infections that can be transmitted from animals to humans. ${ }^{5}$ Bats are associated with SARS, they are considered as important reservoirs and vectors for the exponential spread of such infectious diseases. ${ }^{6}$

\section{Coronavirus}

In the Coronaviridae family of the order Nidovirales, coronaviruses (CoVs) are a diverse group of positive-stranded RNA viruses. Its size is approximately 60 to $140 \mathrm{~nm}$ in diameter. ${ }^{7}$ Their helical structure nucleocapsid is approximately 26 to $32 \mathrm{~kb}$ in size, making it the largest genome among RNA viruses. ${ }^{8}$ Structurally this virus comprises of a large, single-stranded RNA as its genome. A total of four genera of CoVs have been revealed. These are alpha-CoV, beta-CoV, gamma-CoV, and delta-CoV. Among these alpha-CoV and beta-CoV variants are observed to infect mainly the respiratory, gastrointestinal, and central nervous systems of mammals. Whereas gamma-CoV and delta-CoV have been reported infections limited to birds. ${ }^{9}$ COVID-19 is different from SARS-CoV, the etiologic agent for it is SARS-CoV-2, which has the same host receptor: human angiotensin-converting enzyme 2 (ACE2). ${ }^{10}$

\begin{abstract}
${ }^{1}$ Department of Oral Medicine and Radiology, MNDAV Dental College and Hospital, Solan, Himachal Pradesh, India

${ }^{2}$ Department of Oral Medicine and Radiology, Narsinhbhai Patel Dental College and Hospital, Ahmedabad, Gujarat, India

${ }^{3}$ Department of Oral Pathology and Microbiology, MNDAV Dental College and Hospital, Solan, Himachal Pradesh, India

${ }^{4}$ Department of Conservative and Endodontics, MNDAV Dental College and Hospital, Solan, Himachal Pradesh, India

Corresponding Author: Pavan K Gujjar, Department of Oral Pathology and Microbiology, MNDAV Dental College and Hospital, Solan, Himachal Pradesh, India, Phone: +91 8347060388, e-mail: jyopavan2612@gmail.com
\end{abstract}

How to cite this article: Zingade J, Avula S, Gujjar PK, et al. COVID-19: A Review on Recent Pandemic. J Health Sci Res 2021;12(1):8-10.

Source of support: Nil

Conflict of interest: None

\section{EPIDEmiology}

There have been a total of 110,035,633 laboratory-confirmed COVID- 19 cases and 2,429,811 deaths till February 17, 2021. Present studies have suggested that people of all ages are generally susceptible to COVID-19. A higher risk of infection is observed in those who are in close contact with COVID-positive cases, including healthcare workers and other patients within hospitals and clinics. ${ }^{11}$ This new virus has already affected approximately 12.3 million individuals of our planet while claiming 555,769 lives worldwide. ${ }^{12}$

\section{Mode of Transmission}

COVID-19, although zoonotic in origin, is now primarily transmitted from humans to humans. ${ }^{13}$ Transmission mode is through droplets ejected during speaking, coughing, or sneezing; through contact with surfaces directly exposed to the virus; by inhaling aerosols; and now it also spread through feces. So the transmission of COVID-19 is variable and can occur in different circumstances. ${ }^{14}$ 
COVID-19: A Review on Recent Pandemic

Table 1: Classification of COVID-19 patients ${ }^{24}$

\begin{tabular}{|c|c|c|c|c|}
\hline Asymptomatic & Mild & Moderate & Severe & Critical \\
\hline $\begin{array}{l}\text { COVID nucleic acid test } \\
\text { positive. Without any } \\
\text { clinical symptoms and } \\
\text { signs and the chest } \\
\text { imaging is normal }\end{array}$ & $\begin{array}{l}\text { Symptoms of acute upper respiratory } \\
\text { tract infection (fever, fatigue, myalgia, } \\
\text { cough, sore throat, runny nose, sneez- } \\
\text { ing) or digestive symptoms (nausea, } \\
\text { vomiting, abdominal pain, diarrhea) }\end{array}$ & $\begin{array}{l}\text { Pneumonia (frequent } \\
\text { fever, cough) with no } \\
\text { obvious hypoxemia, } \\
\text { chest CT with lesions }\end{array}$ & $\begin{array}{l}\text { Pneumonia } \\
\text { with hypoxemia } \\
\left(\mathrm{SpO}_{2}<92 \%\right)\end{array}$ & $\begin{array}{l}\text { Acute respiratory distress } \\
\text { syndrome (ARDS) may have shock, } \\
\text { encephalopathy, myocardial } \\
\text { injury, heart failure, coagulation } \\
\text { dysfunction, and acute kidney } \\
\text { injury }\end{array}$ \\
\hline
\end{tabular}

Infection may be acquired by the inhalation of this droplet or touching eyes, mouth, nose, or by contacting the surface infected by these droplets. ${ }^{15} \mathrm{~A}$ study revealed that there is no evidence of intrauterine transfer in pregnant ladies infected by SARS-COV-2. ${ }^{16}$

\section{Incubation Period}

The incubation period is 1 to 14 days, and the COVID-19 is contagious during the latency period based on the current epidemiological investigation. It is highly transmissible in humans, especially in the elderly and in immunocompromised people.

SARS-CoV-2 remains viable on surfaces differently, like up to 72 hours on plastic, stainless steel, and other metal surfaces; up to 24 hours on cardboard surfaces; 6 to 12 hours on soft surfaces; 4 to 9 hours on copper surfaces; and up to 3 hours in suspended aerosols. ${ }^{17}$

\section{Etiopathogenesis}

The novel CoV has been a posing threat and has caused havoc all over the world. A SARS disease model consists of three phases: viral replication, immune hyperactivity, and pulmonary destruction. In the lungs, it causes diffuse alveolar damage, epithelial cell proliferation, and an increase of macrophages. Multinucleated giant-cell infiltrates of macrophage or epithelial origin have been associated with fused structure formation, that is, characteristic of many CoV infections. Pathogenesis of SARS is also associated with proinflammatory cytokines, which are released by stimulated macrophages in the alveoli. SARS-CoV infection leads to the stimulation of macrophages that initiates viral replication and viral protein synthesis.

CoVs, enveloped positive-sense RNA viruses, are typified by club-like spikes that project from their surface, an unusually large RNA genome, and a sole replication strategy. Zhao et al. suggested that the receptor for SARS-CoV-2 is ACE2. ACE2 is expressed on type I and II alveolar epithelial cells of the human lung. Men have a higher ACE2 level in their alveolar cells than women. The damage of alveolar cells caused by the binding of SARS-COV-2 on ACE2, which may trigger the sequence of systemic reactions and even death. ${ }^{18}$ Lymphopenia and increasing viral load in the first 10 days of SARS suggest the severity of SARS-CoV.

The rapid decrease in both CD4 and CD8 T cells may be associated with the immunocompromised condition. Direct viral infection due to the absence of ACE2 expression in T- and B-cell lymphocytes and apoptosis of uninfected lymphocytes causes lymphopenia in SARS patients. ${ }^{19}$ They concluded that the immune response against the SARS-CoV is different from that in other viral infections or that the virus is using an unusual strategy to evade the host immune system causing the disease severity.

Sars-CoV-2 expresses membrane proteins that permit adhesion between it and specific receptors expressed on the surface of host tissue cells. The most common virus receptor that is present at high concentrations in lungs, myocardial cells, and kidneys, as well as on oral mucosa especially of the salivary glands and tongue is ACE-2, which is involved in the cell interaction. These structures have been considered as early targets of Sars-CoV-2 (COVID-19). ${ }^{20}$

\section{Clinical Manifestations}

There is a severe effect on one's social life, since all mass gatherings and social events are being avoided to reduce the transmission rates since the outbreak of COVID-19. The severe or death patients with 2019-nCoV infection were mostly old age with comorbidities. Males are most commonly affected. The mean age is generally between 49 and 61 years. ${ }^{21}$ The progression of $\mathrm{CoV}$ is in three different stages, such as mild, moderate, and severe. COVID-19 typically is present with systemic and/or respiratory manifestations. Some infected with SARS-CoV-2 are asymptomatic and can act as carriers.

COVID-19, a disease that manifests in symptoms of high fever and dry cough, and in advanced cases, patients may have respiratory distress. In addition, patients may endure different symptoms such as nausea, vomiting, diarrhea, dizziness, muscle-joint pain, myalgia, or fatigue, hemoptysis, and loss of appetite (Table 1).

In severe cases, immunocompromised conditions, such as hypertension and diabetes mellitus, leads to pneumonia, severe respiratory failure, kidney failure, and death may occur (Sabino-Silva, Jardim \& Siqueira, 2020). ${ }^{22,23}$

\section{InVESTIGATIONS}

Patients with COVID-19 have demonstrated high viral loads in their upper and lower respiratory tracts in the first 5 to 6 days of the onset of symptoms. ${ }^{25}$ A nasopharyngeal (NP) swab or an oropharyngeal (OP) swab is recommended for screening or diagnosis of early infection. ${ }^{26}$ In order to obtain an NP swab specimen, the swab must be inserted deeply into the nasal cavity. Swabs should be kept in place for 10 seconds while being rotated three times. Swabs should have collected nontoxic synthetic fibers, such as polyester, as well as synthetic nylon handles. ${ }^{27}$

Self-collected saliva specimen is another alternative option for collecting an upper respiratory tract specimen to evaluate patients with suspected COVID-19 pneumonia. ${ }^{28}$

Repeated testing may be particularly important if a patient has a clinical picture of viral pneumonia, a potential exposure history, and/or radiographic finding in chest computed tomography (CT) or magnetic resonance imaging scan.

The highest viral load is present in the lower respiratory tract, the sputum sampling or bronchoalveolar lavage should be used for collecting specimens for the diagnosis of COVID-19. ${ }^{29}$ Patients with severe pneumonia and ARDS may require emergent intubation and respiratory isolation in a negative-pressure room. During the intubation procedure, the lower respiratory tract sputum specimen can be collected. ${ }^{30}$ Thus, apart from direct respiratory sampling, a rectal swab and real-time RT-PCR methods can be preferred for detecting SARS-CoV-2. ${ }^{31}$ 


\section{Precautions}

Interim guidelines for the collection, handling, and testing of clinical specimens that might contain SARS-CoV-2 have been released by the Centre for Disease Control and Prevention and the WHO. The guidelines for the prevention and spread of disease are given, such as hygiene maintenance, use of biocidal agents, social distancing, and quarantine people.

As the risk of transmissions of CoV from humans to humans is more and social distancing is the best way for precautions. Thus, the COVID-19 outbreak must be controlled by certain strict and mandatory precautions to stop this dangerous devil virus. Also, it is a major task for all global scientists to find out an effective counteractive drug to control this deadly CoV. Thus, considering the depth of the spread of CoV and its impact on global health, it is necessary to know the dos and don'ts for the persistence, precautions, and diagnostic strategies against the challenging COVID-19. ${ }^{32}$

\section{Conclusion}

The COVID-19 pandemic is an existing issue affecting people worldwide. Without fundamental therapeutic interventions, current management is to reduce the virus spread and provide supportive care for diseased patients. The best cleaning sanitization and hygiene practices could control this recent and most challenging disease, but not limited to this, there is a need for a permanent solution for the diminution of COVID-19, globally.

\section{References}

1. Tyrrel, DAJ, Almedia JD, Berry DM, et al. Coronavirus. Nature 1968;220:650. DOI: 10.1038/220650b0.

2. Aldahlawi SA, Afif IK. COVID-19 in dental practice: transmission risk, infection control challenge, and clinical implications. Open Dent J 2020;14:348-354. DOI: 10.2174/1874210602014010348.

3. Ouassou H, Kharchoufa L, Bouhrim M, et al. The pathogenesis of coronavirus disease 2019 (COVID-19): evaluation and prevention. J Immunol Res 2020;2020:1357983. DOI: 10.1155/2020/1357983.

4. Atas O, Yildirim TT. Evaluation of knowledge, attitudes, and clinical education of dental students about COVID-19 pandemic. PeerJ 2020;2020:9575. DOI: 10.7717/peerj.9575.

5. Cantas L, Suer K. Review: the important bacterial zoonoses in "One Health" concept. Front Public Health 2014;2:144. DOI: 10.3389/ fpubh.2014.00144.

6. Villani FA, Aiuto R, Paglia L et al. COVID-19 and dentistry: prevention in dental practice, a literature review. Int J Environ Res Public Health 2020;17:4609. DOI: 10.3390/ijerph17124609.

7. Bhardwaj SS, Alduwayhi S, Bhardwaj A. COVID-19, various treatment options and special considerations for dentistry. J Pharm Res Int 2020;32(10):70-76. DOI: 10.9734/jpri/2020/v32i1030494.

8. Fallahi HR, Keyhan SO, Zandian D, et al. Being a front-line dentist during the Covid-19 pandemic: a literature review. Maxillofac Plast Reconstr Surg 2020;42:12. DOI: 10.1186/s40902-020-00256-5.

9. Su S, Wong G, Shi W, et al. Epidemiology, genetic recombination, and pathogenesis of coronaviruses. Trends Microbiol 2016;24: 490-502. DOI: 10.1016/j.tim.2016.03.003.

10. Kamate SK, Sharma S, Thakar S, et al. Assessing knowledge, attitudes and practices of dental practitioners regarding the COVID-19 pandemic: a multinational study. Dent Med Probl 2020;57(1):11-17. DOI: 10.17219/dmp/119743.

11. Spagnuolo G, De Vito D, Rengo S, et al. COVID-19 outbreak: an overview on dentistry. Int J Environ Res Public Health 2020;17:2094. DOI: 10.3390/ijerph17062094.

12. Hua F, Qin D, Yan J, et al. COVID-19 related experience, knowledge, attitude, and behaviors among 2,669 orthodontists, orthodontic residents, and nurses in China: a cross-sectional survey. Front Med 2020;7:481. DOI: 10.3389/fmed.2020.00481.

13. COVID.19 and dental preparedness. J Dent Defence Sect. 2020. Available at: http://www.journaldds.org

14. Gupta P, Bhagyalakshmi A, Mehta P. COVID-19: a dental perspective. Int J Community Med Public Health 2020;7(5):1994-1997. DOI: 10.18203/2394-6040.ijcmph20202020.

15. Khatod $S$, Ikhar A, Nikhade $P$, et al. Preventive measures for dental professionals during worldwide emergency COVID-19. Int J Res Pharm Sci 2020;11(1):150-153. Available at: https://pharmascope.org/index. php/ijrps. DOI: https://doi.org/10.26452/ijrps.v11iSPL1.

16. Chen $\mathrm{D}$, Yang $\mathrm{H}, \mathrm{Cao} \mathrm{Y}$, et al. Expert consensus for managing pregnant women and neonates born to mothers with suspected or confirmed novel coronavirus (COVID-h19) infection. Int J Gynaecol Obstet 2020;149(2):130-136. DOI: 10.1002/ijgo.13146.

17. Rothan HA, Byrareddy SN. The epidemiology and pathogenesis of coronavirus disease (COVID-19) outbreak. J Autoimmunity 2020;109:102433. DOI: 10.1016/j.jaut.2020.102433.

18. Srivastava S, Tandon P. Dealing with dental patients during and after coronavirus disease 2019 outbreak. Indian J Dent Sci 2020;12:3. Available at: http://www.ijds.in/text.asp?2020/12/3/172/292279 DOI: 10.4103/IJDS.IJDS_54_20.

19. Rajalakshmi G, Sarika K. COVID-ified dentistry: clinical dentistry in COVID era. Int J Sci Healthcare Res 2020;5:2. Available at: https://ijshr. com/IJSHR_Vol.5_Issue.2_April2020/IJSHR0048.pdf

20. Chen N, Zhou M, Dong $X$, et al. Epidemiological and clinical characteristics of 99 cases of 2019 novel coronavirus pneumonia in Wuhan, China: a descriptive study. Lancet 2020;395(10223):507-513. DOI: 10.1016/S0140-6736(20)30211-7.

21. Huang C, Wang Y, Li X, et al. Clinical features of patients infected with 2019 novel coronavirus in Wuhan, China. Lancet 2020;395(10223):497506. DOI: 10.1016/S0140-6736(20)30183-5.

22. Peiris JS, Yuen $K Y$, Oserhaus $A D$, et al. The severe acute respiratory syndrome. N Eng J Med 2003;349(25):2431-2441. DOI: 10.1056/ NEJMra032498.

23. Guan W, Ni Z, Hu Y, et al. Clinical characteristics of coronavirus disease 2019 in China. N Eng J Med 2020;382:1708-1720. DOI: 10.1056/ NEJMOa2002032.e.

24. Koichi Y, Fujiogi M, Koutsogiannaki S. COVID-19 pathophysiology: a review. Clin Immunol 2020;215:108427. DOI: 10.1016/j. clim.2020.108427.

25. Pan Y, Zhang D, Yang P, et al. Viral load of SARS-CoV-2 in clinical samples. Lancet Infect Dis 2020;24:30113-30114. DOI: 10.1016/S14733099(20)30113-4.

26. Zou L, Ruan F, Huang M, et al. SARS-CoV-2 viral load in upper respiratory specimens of infected patients. N Engl J Med 2020;382:1177-1179. DOI: 10.1056/NEJMc2001737.

27. To KK, Tsang OT, Leung WS, et al. Temporal profiles of viral load in posterior oropharyngeal saliva samples and serum antibody responses during infection by SARS CoV-2: an observational cohort study. Lancet Infect Dis 2020;23:30196-30191. DOI: 10.1016/S14733099(20)30196-1.

28. Wolfel R, Corman VM, Guggemos W, et al. Virological assessment of hospitalized patients with COVID-2019. Nature 2020;581(7809):465469. DOI: 10.1038/s41586-020-2196-x.

29. Chan PK, To WK, Ng KC, et al. Laboratory diagnosis of SARS. Emerg Infect Dis 2004;10:825-831. DOI: 10.3201/eid1005.030682.

30. Kim C, Ahmed JA, Eidex RB, et al. Comparison of nasopharyngeal and oropharyngeal swabs for the diagnosis of eight respiratory viruses by real-time reverse transcription-PCR assays. PLoS One 2011;6:e21610. DOI: 10.1371 /journal.pone.0021610.

31. Druce J, Garcia K, Tran T, et al. Evaluation of swabs, transport media, and specimen transport conditions for optimal detection of viruses by PCR. J Clin Microbiol 2012;50:1064-1065. DOI: 10.1128/ JCM.06551-11.

32. To KK, Lu L, Yip CC, et al. Additional molecular testing of saliva specimens improves the detection of respiratory viruses. Emerg Microbes Infect 2017;6:e49. DOI: 10.1038/emi.2017.35. 